\title{
Co-relation between childhood asthma and serum vitamin D levels - a cross sectional study
}

\author{
Venkatesha K.R. ${ }^{1}$, Naik R.R.K. ${ }^{2}$ \\ ${ }^{1}$ Dr. Venkatesha K.R., Associate Professor, ${ }^{2}$ Dr. R Ravikumar Naik, Professor; both authors are affiliated with \\ Department of Paediatrics, Sapthagiri Institute of Medical Sciences, Bengaluru, Karnataka, India. \\ Corresponding Author: Dr. R. Ravikumar Naik, No-32/2d, Nandini Creast Apartment, Nandi View Layout, Dinnur \\ Main Road, R.T. Nagar, Bangalore, Karnataka, India. Email: pediatricdr25@gmail.com
}

\begin{abstract}
Introduction: Asthma is a word of Greek origin that means to "breathe hard" or "to pant". One of the first persons to write about asthma was Hippocrates. He was able to recognize the spasmodic nature of the disease and believed its onset to be caused by moisture, occupation and climate. Objective: To evaluate serum Vitamin D levels in children's suffering from asthma. Methodology: It is a cross sectional study was undertaken in children with asthma. Results: out of 110 asthmatics, 28 cases were in the age group of 1-5 years, 49 cases were in the age group 6-12 years, 33 cases were in the age group of 13-18 years and out of 110 asthmatic children 68 cases were male and 32 cases were females, 14 children were in the age group of 1-5 years had deficient Vitamin D levels, 10 children's had insufficient levels and 4 children's had sufficient levels of Vitamin D, 28 children were in the age group of 6-12 years had deficient Vitamin D levels, 14 children's had insufficient levels and 7 children's had sufficient levels of Vitamin D, 21 children were in the age group of 13-18 years had deficient Vitamin D levels. Conclusion: There has been a growing interest in the potential role of vitamin $\mathrm{D}$ in asthma management, because it might help to reduce upper respiratory infections that can lead to exacerbations of asthma. Several clinical trials have tested whether taking vitamin D as a supplement has an effect on asthma attacks, symptoms, and lung function in children.
\end{abstract}

Key words: Children, Asthma, Vitamin D

\section{Introduction}

Asthma is a word of Greek origin that means to "breathe hard" or "to pant". One of the first persons to write about asthma was Hippocrates. He was able to recognize the spasmodic nature of the disease and believed its onset to be caused by moisture, occupation and climate. He suspected that asthma was comparable to epilepsy and had its own nature arising from external cause. In 1968 Sir John Floyer in his book "A Treaties of Asthma" have said that asthma is due to the constriction of bronchi. He also distinguished between different "species" of asthma by contrasting continuous asthma with periodic or convulsive asthma. He also found that elements of the environment could trigger asthma attacks.

Vitamin D is not a true vitamin, because individuals with adequate exposure to sunlight do not require any dietary supplements. It is steroid hormone acting on

Manuscript received: $9^{\text {th }}$ December 2018

Reviewed: $20^{\text {th }}$ December 2018

Author Corrected: $26^{\text {th }}$ December 2018

Accepted for Publication: $31^{\text {st }}$ December 2018 specific cell receptor to regulate the various tissue processes. Vitamin D2 (ergocalciferol), obtained from influence of ultraviolet B radiations (UV-B) on plants and yeast and Vitamin D3 (cholecalciferol), produced in skin by UV-B are the two main forms of Vitamin D. Both forms are metabolized similarly in the body, first by hepatic 25 hydroxylation into inactive but stable 25 hydroxy Vitamin D [25(OH)-D] cholecalciferol (Calcidiol) and then by renal hydroxylation into active but unstable 1, 25 dihydroxy Vitamin D [1, 25(OH) 2D] cholecalciferol (Calcitriol). The term-Vitamin D deficiencyll does not necessarily connote clinically explicit disease, rather it means an increase in risk for certain diseases and that also explains the seeming paradox that individuals who are ostensibly healthy today may nevertheless be deficient [1].

Vitamin D deficiency or insufficiency has likely increased in the United States over the last decade. In a recent study of 9,757 United States subjects 1 to 21 years of age, approximately $9 \%$ and approximately $61 \%$ 


\section{Original Research Article}

of participants had Vitamin D deficiency and insufficiency respectively. Reduced Vitamin D levels have been found in populations living near the Equator (e.g., in Saudi Arabia, Israel, India, and Costa Rica and in the south-eastern United States), suggesting that lifestyle can have major effects on Vitamin D status regardless of latitude.

There is a controversy regarding the normal levels of deficiency and insufficiency $[2,3]$.

\section{Objective}

To evaluate serum Vitamin D levels in children's suffering from asthma

\section{Methodology}

Place of study: Sapthagiri Institute of Medical Sciences, Bengaluru

Type of study: A cross sectional study

Study duration: January 2017 to December 2017.

Inclusion criteria: all the children suffering from asthma attending paediatrics department

Exclusion criteria: Congenital anomaly of lungs

\section{Results}

Table-1: Age \& Sex Wise Distribution of Asthma Cases

\begin{tabular}{|c|c|c|c|}
\hline Age group & Male & Female & Total \\
\hline 1-5 Years & 16 & 12 & 28 \\
\hline 6-12 Years & 30 & 19 & 49 \\
\hline 13-18 Years & 22 & 11 & 33 \\
\hline Total & $\mathbf{6 8}$ & $\mathbf{4 2}$ & $\mathbf{1 1 0}$ \\
\hline
\end{tabular}

In the present study done, out of 110 asthmatics, 28 cases were in the age group of 1-5 years, 49 cases were in the age group 6-12 years, 33 cases were in the age group of 13-18 years and out of 110 asthmatic children 68 cases were male and 32 cases were females.

Table-2: Vitamin D Status versus Severity of Asthma

\begin{tabular}{|c|c|c|c|c|}
\hline Age group & Deficient & Insufficient & Sufficient & Total \\
\hline 1-5 Years & 14 & 10 & 4 & 28 \\
\hline 6-12 Years & 28 & 14 & 7 & 39 \\
\hline 13-18 Years & 21 & 10 & 2 & $\mathbf{1 1 0}$ \\
\hline Total & $\mathbf{6 3}$ & $\mathbf{3 4}$ & $\mathbf{1 3}$ & \\
\hline
\end{tabular}

In the present study, 14 children were in the age group of 1-5 years had deficient Vitamin D levels, 10 children's had insufficient levels and 4 children's had sufficient levels of Vitamin D.

In the present study, 28 children were in the age group of 6-12 years had deficient Vitamin D levels, 14 children's had insufficient levels and 7 children's had sufficient levels of Vitamin D.

In the present study, 21 children were in the age group of 13-18 years had deficient Vitamin D levels, 10 children's had insufficient levels and 2 children's had sufficient levels of Vitamin D.

\section{Discussion}

In a 6-month clinical trial of Vitamin D3 supplementation (500 IU/d) as adjuvant therapy to ICS to reduce asthma morbidity in 48 Polish children by Majak et al it was found that there was reduced the risk of asthma exacerbation triggered by acute respiratory tract infection in the Vitamin D supplemented group [4]. In the present study done, 14 children were in the age group of 1-5 years had deficient Vitamin D levels,
10 children's had insufficient levels and 4 children's had sufficient levels of Vitamin D, 28 children were in the age group of 6-12 years had deficient Vitamin D levels, 14 children's had insufficient levels and 7 children's had sufficient levels of Vitamin D, 21 children were in the age group of 13-18 years had deficient Vitamin D levels, 10 children's had insufficient levels and 2 children's had sufficient levels of Vitamin D. 
Another study by Chinellato et al showed that Vitamin D level inversely correlated with exercise-induced bronchoconstriction in Italian children with asthma [5].

In the present study done, out of 110 asthmatics, 28 cases were in the age group of 1-5 years, 49cases were in the age group 6-12 years, 33 cases were in the age group of 13-18 years and out of 110 asthmatic children 68 cases were male and 32 cases were females. In a retrospective cohort study assessing maternal intake of Vitamin D during pregnancy and risk of recurrent wheeze in children at 3 years of age it was found that increasing maternal Vitamin D intake during pregnancy decreased the risk of wheeze symptoms in early childhood [6].

In a study done by Korn et al in Germany in 280 adult asthmatics, it was found that $25(\mathrm{OH}) \mathrm{D}$ levels below $30 \mathrm{ng} / \mathrm{ml}$ were common in adult asthma and most pronounced in patients with severe and/or uncontrolled asthma [7].

In a Cross-sectional study of 54 adults with persistent asthma in Denver, Colorado, serum Vitamin D was positively correlated with FEV1, glucocorticoid response and Vitamin D insufficiency or deficiency, (30ng/ml) was associated with airway hyper responsiveness [8].

A cross-sectional study of 7,648 Finnish adults at 31 years of age found that lack of Vitamin D supplementation (assessed in infancy) was associated with increased risk of asthma. However, this study lacked Vitamin D measures and had inadequate followup data on study participants [9].

Another study by Freishtat et al which was a casecontrol study of 106 African American subjects 6 to 20 years of age found strong positive association between Vitamin D insufficiency and deficiency and asthma in African Americans [10].

In a study by Kavitha et.al., asthma status of 50 (47.6\%) children were categorized as controlled, $32(30.5 \%)$ as partly controlled, and 23 (21.9\%) as uncontrolled. Table II compares the pulmonary function tests (PFT) values between these groups. The median (IQR) serum $25(\mathrm{OH})$ D level in the study participants was $9(6,14) \mathrm{ng} / \mathrm{mL}$. The median serum $25(\mathrm{OH})$ D levels were comparable in the three groups based on control of asthma. The prevalence of vitamin D deficiency in uncontrolled asthma group was higher with $78.2 \%$ children being vitamin $\mathrm{D}$ deficient $(\mathrm{P}=0.52)$ (Table III). None of the major spirometric parameters showed statistically significant correlation with serum vitamin $\mathrm{D}$ level except FEF25 (\% predicted) $(\mathrm{r}=0.22 ; \mathrm{P}=0.02)$ and PEFR ( $\mathrm{r}=0.19 ; \mathrm{P}=0.049$ ). The asthma control subgroups did not show any significant seasonal differences with the time of sampling. Median (IQR) cumulative inhaled steroid use were $423(214.5,684) \mathrm{mg}, 456(241.5,576)$ $\mathrm{mg}$, and $363(330,600) \mathrm{mg}$ in deficient, insufficient and sufficient vitamin $\mathrm{D}$ status groups $(\mathrm{P}=0.98)$. Daily sunlight exposure was comparable in vitamin $\mathrm{D}$ sufficient participants and others $(\mathrm{P}=0.97)$ [11].

In a case-control study, Awasthi, et al. reported significant association between asthma control and vitamin D deficiency. In another study, vitamin D levels were lower in children with severe treatment resistant asthma as compared to moderate asthma group and control subjects. In a cross-sectional study among 100 children, Searing, et al. reported positive correlation between vitamin D levels and FEV1 (percent predicted) and FEV1/FVC. On the other hand, a study done in Thailand by Krobtrakulchai, et al. in 125 asthmatic children, vitamin D levels were similar between three asthma control groups, and there was no association between vitamin D levels and PFT values. Recent trials in children and adults with asthma have also failed to demonstrate the effect of vitamin D supplementation on symptom control [12- 17].

There is growing literature suggesting a link between Vitamin D deficiency and asthma in children, but systematic reviews are lacking. The aim of this study is to evaluate the prevalence of Vitamin D deficiency in asthmatic children and to assess the correlations of Vitamin D levels with asthma incidence, asthma control, and lung functions. PubMed, EMBASE, and Cochrane Library were searched for observational studies on asthma and Vitamin D. Two authors independently extracted data. Meta-analysis was performed using the Review Manager Software. A total of 23 (11 case-control, 5 cohort, and 7 cross-sectional) studies enrolling 13,160 participants were included in the review. Overall, Vitamin D deficiency and insufficiency were prevalent in $28.5 \%$ and $26.7 \%$ children with asthma, respectively.

The mean 25-hydroxyvitamin D (25(OH)D) levels (10 studies) were significantly lower in asthmatic children as compared to nonasthmatic children with a mean difference of -9.41 (95\% confidence interval [CI] $-16.57,-2.25)$. The odds ratio of Vitamin D deficiency (eight case-control studies) was significantly higher among asthmatic children as compared to nonasthmatic children (odds ratio 3.41; 95\% CI 2.04, 5.69). Correlations between Vitamin D levels and incidence of 


\section{Original Research Article}

asthma, lung functions, and control of asthma had mixed results. To conclude, asthmatic children had lower $25(\mathrm{OH}) \mathrm{D}$ levels as compared to nonasthmatic children, but the correlations between 25(OH)D and asthma incidence, asthma control, and lung functions were varied. Well-designed randomized controlled trials are required to determine if children with asthma can benefit from Vitamin D supplementation [18].

Brehm et al. evaluated correlation between Vitamin D levels and asthma exacerbations in children after adjusting for time spent outdoors and racial ancestry and found that there was still a strong association between Vitamin $D$ deficiency and asthma exacerbations after adjusting these factors. Therefore, this reverse causation seems to be less plausible. A recent review of observational studies by Cassim et al. included both children and adult patients and identified 23 studies (12 cohort, 9 cross-sectional, and 2 casecontrol studies) and reported that higher Vitamin D levels were associated with decreased risk of acute exacerbations of asthma.

Similar to our review, they also reported mixed results for association of Vitamin D levels with prevalence, incidence, and severity of asthma. This review also included studies where Vitamin D levels were measured during pregnancy. We excluded such studies, therefore number of cohort studies were less in our review. Yadav and Mittal conducted a randomized controlled trial of oral Vitamin D3 (cholecalciferol) supplementation of $60,000 \mathrm{IU}$ per month for 6 months in children and reported better peak expiratory flow rate improvement, better asthma control, and reduced need of emergency visit and oral steroids use in Vitamin D group compared to placebo group. However, the Vitamin D levels were not measured in the study.

In another pediatric RCT, 500 units of Vitamin D supplementation daily for 6 months showed decreased asthma exacerbation in Vitamin D group though Vitamin D levels did not change before and after supplementation and lung function improved significantly in both arms. The Vitamin D assessment (VIDA) trial randomized 408 adults with poorly controlled asthma to supplement with high-dose Vitamin D or placebo. Vitamin D supplementation did not alter the rate of first treatment failure during 28 weeks. In a subgroup analysis, subjects with a rise in Vitamin D levels $>30 \mathrm{ng} / \mathrm{ml}$ had decreased rate of treatment failure and acute asthma exacerbations compared to placebo. These trials suggest that Vitamin D supplementation will not be of help in all asthmatic children but in certain group of children [19-23].

\section{Conclusion}

Low blood levels of vitamin D have been linked to increased risk of asthma attacks in children.

There has been a growing interest in the potential role of vitamin D in asthma management, because it might help to reduce upper respiratory infections that can lead to exacerbations of asthma.

Several clinical trials have tested whether taking vitamin D as a supplement has an effect on asthma attacks, symptoms, and lung function in children.

\section{What this study adds?}

Asthmatic children had significantly lower Vitamin D levels.

\section{References}

1. Heaney RP. Vitamin D in health and disease. Clin J Am Soc Nephrol. 2008 Sep;3(5):1535-41. doi: 10.2215/CJN.01160308. Epub 2008 Jun 4.

2. Ross AC, Manson JE, Abrams SA, et al. The 2011 report on dietary reference intakes for calcium and vitamin $\mathrm{D}$ from the Institute of Medicine: what clinicians need to know. J Clin Endocrinol Metab. 2011 Jan;96(1):53-8. doi: 10.1210/jc.2010-2704. Epub 2010 Nov 29.

3. Holick MF. Vitamin D deficiency. N Engl J Med. 2007 Jul 19;357(3):266-81. DOI:10.1056/ NEJMra070553

4. Majak P, Olszowiec CM, Smejda K, Stelmach I. Vitamin D supplementation in children may prevent asthma exacerbation triggered by acute respiratory infection. J Allergy ClinImmunol-2011;127:1294-96.

5. Chinellato I, Piazza M, Sandri M, Peroni G, Cardinale F, Piacentini L. Serum vitamin D levels and exercise-induced bronchoconstriction in children with asthma. Eur Respir J-2011;37:1366-70.

6. Camargo A, Rifas-Shiman L, Litonjua A, Edwards W, Weiss T, Gold R, Kleinman K. Maternal intake of vitamin $\mathrm{D}$ during pregnancy and risk of recurrent wheeze in children at $3 \mathrm{y}$ of age. Am J ClinNutr2007;85:788-95.

7. Korn S, Hübner M, Jung M, et al. Severe and uncontrolled adult asthma is associated with vitamin D insufficiency and deficiency. Respir Res. 2013 Feb 22;14:25. doi: 10.1186/1465-9921-14-25. 
8. Sutherland ER, Goleva E, Jackson LP, et al. Vitamin D levels, lung function, and steroid response in adult asthma. Am J Respir Crit Care Med. 2010 Apr 1;181(7):699-704. doi: 10.1164/rccm.200911-1710OC. Epub 2010 Jan 14.

9. Hyppönen $E^{1}$, Sovio U, Wjst M, et al. Infant vitamin $\mathrm{d}$ supplementation and allergic conditions in adulthood: northern Finland birth cohort 1966. Ann N Y Acad Sci. 2004 Dec;1037:84-95. DOI:10. 1196/ annals. 1337.013

10. Freishtat RJ, Iqbal SF, Pillai DK, et al. High prevalence of vitamin D deficiency among inner-city African American youth with asthma in Washington, DC. J Pediatr. 2010 Jun;156(6):948-952. doi: 10.1016/j. jpeds.2009.12.033. Epub 2010 Mar 16.

11. Kavitha TK, Gupta N, Kabra SK, et al. Association of Serum Vitamin D Levels with Level of Control of Childhood Asthma. Indian Pediatr. 2017 Jan 15;54(1): 29-32.

12. Awasthi S, Vikram K. Serum 25 hydroxy vitamin D insufficiency associated with bronchial asthma in Lucknow, India. Indian J Pediatr. 2014 Jul;81(7):644-9. doi: 10.1007/s12098-013-1310-6. Epub 2014 Jan 21.

13. Gupta A, Sjoukes A, Richards D, et al. Relationship between serum vitamin $\mathrm{D}$, disease severity, and airway remodeling in children with asthma. Am J Respir Crit Care Med. 2011 Dec 15;184(12):1342-9. doi: 10.1164/rccm.201107-1239OC. Epub 2011 Sep 8.

14. Searing DA, Zhang Y, Murphy JR, Hauk PJ, Goleva E, Leung DYM. Decreased serum vitamin D levels in children with asthma are associated with increased corticosteroid use. J Allergy Clin Immunol-2010; 125:995-1000.

15. Krobtrakulchai W, Praikanahok J, Visitsunthorn N, Vichyanond P, Manonukul K, Pratumvinit B, et al. The effect of vitamin D status on pediatric asthma at a university hospital, Thailand. Allergy Asthma Immunol Res-2013;5:289-94.
Original Research Article

16. Lewis E, Fernandez C, Nella A, et al. Relationship of 25-hydroxyvitamin D and asthma control in children. Ann Allergy Asthma Immunol. 2012 Apr;108(4):281-2. doi: 10.1016/j.anai.2012.01.003.

17. Bar Yoseph R, Livnat G, Schnapp Z, et al. The effect of vitamin $\mathrm{D}$ on airway reactivity and inflammation in asthmatic children: A double-blind placebo-controlled trial. Pediatr Pulmonol. 2015 Aug;50(8):747-53. doi: 10.1002/ppul.23076. Epub 2014 Jul 2.

18. Jat KR, Khairwa A. Vitamin D and asthma in children: A systematic review and meta-analysis of observational studies. Lung India. 2017 JulAug;34(4):355-363. doi: 10.4103/0970-2113.209227.

19. Brehm JM, Acosta-Pérez E, Klei L, et al. Vitamin D insufficiency and severe asthma exacerbations in Puerto Rican children. Am J Respir Crit Care Med. 2012 Jul 15;186(2):140-6. doi: 10.1164/rccm.201203-0431OC. Epub 2012 May 31.

20. Cassim R, Russell MA, Lodge CJ, et al. The role of circulating 25 hydroxyvitamin $\mathrm{D}$ in asthma: a systematic review. Allergy. 2015 Apr;70(4):339-54. doi: 10.1111/all.12583.

21. Yadav M, Mittal K. Effect of vitamin D supplementation on moderate to severe bronchial asthma. Indian J Pediatr. 2014 Jul;81(7):650-4. doi: 10.1007/s12098-013-1268-4. Epub 2013 Nov 6.

22. Majak P, Olszowiec-Chlebna M, Smejda K, et al. Vitamin D supplementation in children may prevent asthma exacerbation triggered by acute respiratory infection. J Allergy Clin Immunol. 2011 May;127(5): 1294-6. doi: 10.1016/j.jaci.2010.12.016. Epub 2011 Feb 18.

23. Castro M, King TS, Kunselman SJ, et al. Effect of vitamin D3 on asthma treatment failures in adults with symptomatic asthma and lower vitamin D levels: the VIDA randomized clinical trial. JAMA. 2014 May;311 (20):2083-91. doi: 10.1001/jama.2014.5052.

\section{How to cite this article?}

Venkatesha K.R, Naik R.R.K. Co-relation between childhood asthma and serum vitamin D levels - a cross sectional study. Int J Pediatr Res. 2018;5(12):642-646.doi:10.17511/ijpr.2018.i12.06. 